Accident Prevention also recommends that drivers who have had a myocardial infarction should not hold an H.G.V. licence. ${ }^{7}-\mathrm{I}$ am, etc.

ANDREW RAFFLE Chairman of Transport Committee Medical Commission on Accident Prevention

London N.W.1

Joint Working Party, fournal of the Royal College of Physicians, 1975, 9, 281.

Road Traffic Act 1972

Transactions of the Medical P.

W'einblatt, E., et al. American fournal of Public Health, $1968,58,1329$

Peterson, B. J., and Petty, C. S., Fournal of Forensic Science, 1962, 7, 274

Gissane, W., and Bull, J., British Medical fournal, $1973,1,67$

7 Medical Commission on Accident Prevention, Medical Aspects of Fitness to Drive, 2nd edn. (revised). London, M.C.A.P., 1974.

\section{Prevention of Tetanus in the Wounded}

SIR,-It was with some dismay that I read the paper by Dr. J. W. G. Smith and others (23 August, p. 453) advocating a wider use of human immunoglobulin in the preven tion of tetanus. I fear that their views, if widely propagated, will lead to a vast and unnecessary increase in the use of human immunoglobulin and that we shall revert to its use for protection against medicolegal proceedings rather than the protection of the patient.

Though they emphasized that their views are to be taken only as guide lines, there are a vast number of people whose immunity status is unknown, who have not had a complete course of toxoid, or whose last booster was over 10 years ago. Similarly, there are a large number of wounds which are over six hours old when they reach the theatre, which cannot be adjudged wholly "clean," and which have more than "negligible tissue damage."

In an accident and emergency unit dealing with over 50000 new patients a year, of whom $70 \%$ have suffered trauma, no patient with tetanus has been seen since the unit opened seven years ago. Adsorbed tetanus toxoid, either initiating a course or as a booster where necessary, is used routinely, combined with adequate surgical treatment of the wound. Antibiotics are used only for badly contaminated lacerations. This, to my mind, is the rational approach to tetanus in our society rather than endeavouring on rather vague premises to give better protection to the one in over 100000 lacerations likely to be at risk.

Royal Sussex County Hospital,

AUstin BRown Brighton

\section{Training for Overseas Graduates}

SIR,-Drs. B. Senewiratne and $M$ Kanagarajah in their article on postgraduate training in a developing country (26 July, p. 213) stress that if Britain and other developed countries are to make a real contribution to medicine in developing countries they should accept some doctors for training with the emphasis on work rather than passing examinations.

In 1972 I had the good fortune to work for three months in Ceylon, teaching undergraduate and postgraduate students. Since that time I have had a succession of Ceylon graduates who have come to work in this unit for a month at a time before going on to work in other parts of the country. As a result of this experience I wrote to the British Council saying that it seemed to me that one answer to the problem of training overseas postgraduates would be to establish specific training posts. For example, in this unit we have a fairly comprehensive training programme in neurology, but the posts are filled by direct competition and this makes it very difficult for overseas graduates. I suggested a fellowship which would be filled only by graduates who had been specially selected by their own country's doctors with a view to returning to a consultant post. The British Council were interested and sent this proposal on to the Overseas Development Administration, from which nothing further has been heard.

There must be many hospitals in this country where a training fellowship of the type visualized by Drs. Senewiratne and Kanagarajah could easily be established. If some relatively independent body such as the British Council or the British Postgraduate Medical Federation were to set up a register of such posts and send lists of these posts to medical schools in developing countries, then at least some of the problems raised by Drs. Senewiratne and Kanagarajah would be answered. It should be a simple matter to meet the cost of these training fellowships (which would simply be a registrar's salary) from money such as the Commonwealth educational co-operation funds of the British Council or some similar source. I would also suggest that once these travelling fellowships had been established an exchange scheme at registrar, senior registrar, and consultant level could be contemplated.

If anyone, in Britain or abroad, interested in setting up such a register would write to me I will undertake to present the information to the British Council and the British Postgraduate Medical Federation and to try to get such a register established on a formal basis.-I am, etc.,

Wessex Neurological Centre.

South mpton General Hospital,

Southampton

\section{Who Cares For Head Injuries?}

SIR,-The neurosurgeon is the person best qualified to be responsible for the treatment or patients with head injuries (Professor Bryan Jennett, 2 August, p. 267). Their treatment should be carried out within the accident service, where such an organization exists. This is important in part because more than one-third of these patients with serious head injury have other injuries that require simultaneous treatment. The efficient treatment of this type of patient requires a well-organized team, and the neurosurgeon should also play an important part in deciding when other necessary procedures can be carried out. A small proportion of patients with head injury will need craniotomy. The quality of the decision as to when it is necessary is at least as important as the technical skill in carrying it out, and the neurosurgeon is best qualified to make this decision.

This was the view of the late Professor Sir Hugh Cairns. It was put into effect when the accident service was started in Oxford in 1942 and the policy has since been continued by a series of distinguished neuro- surgeons. One graphic result of this policy was the reduction of the mortality rate from $9 \%$ in the first 1000 cases to just over $3 \%$ in the fourth. Though the $3 \%$ figure was achieved in Oxford about 20 years ago, I believe it is still well below the national average. -I am, etc.

Cuddesdon, Oxford

JAMES C. SCOTT

\section{SI Units}

SIR,-We write to protest at the general introduction of SI units into medicine without adequate consultation with those who have to interpret laboratory reports in the clinical situation.

In our experience this has already led to waste of time and effort, confusion, and danger; and even when we have got used to the units, which involves effort that would be more usefully employed in learning things of real relevance to patient care, the units are in many more instances inappropriate for the range of quantities met with in clinical medicine. It is noticeable when one visits the Continent how at producer and consumer level the old measures of weight etc. are still used instead of the metric system because they represent natural quantities rather than artificial concepts; for instance, a yard as the length of a step is easier to gauge than a fraction of a wrong measure of the circumference of the earth; and the same applies to many measurements used in clinical medicine. We have a particularly difficult task in paediatrics because there are different standards for children of different ages, size, and sex to which we have got used and only pathologists with paediatric experience understand.

There seems to be a kind of general law that when a committee recommends something foolish-like Salmon or Seebohm-its recommendations are immediately put into effect to the detriment of the Service; whereas when it recommends something sensiblelike Briggs-it is shelved.

When the tide is artificially induced there is something to be said for Canute trying to put it in reverse in the interest of efficiency, safety, and common sense.-We are, etc.

JOHN A. DAVIS

University Department of Child Health,

t. Mary's Hospital,

V. MILLER

Division of Paediatrics Booth Hall Children's Hospital,
Manchester

Ischaemic Heart Disease, Vitamins D and A, and Magnesium

SIR,-Professor V. Lindén (14 September 1974, p. 647) has suggested that vitamin A, by protecting against the hypercholesterolaemic effect of vitamin $D$, may influence the incidence of myocardial infarction. His epidemiological study (in Norway) related to relatively high vitamin $\mathbf{D}$ intakes. Vitamin $\mathbf{A}$ also protects against the osteolysis and renal and arterial calcinosis of experimental hypervitaminosis D. ${ }^{1}$ The risk of hypervitaminosis $D$ in the United States, where the greatest source is fortified milk, may be even greater than in northern Norway, where most of the vitamin $D$ derives from fish liver, which is rich in vitamin $A$ 